Vietnam Journal of Mechanics, VAST, Vol. 27, No. 3 (2005), pp. 186-192

\title{
THE GENERAL INTERFERENCE MODEL IN THE FUZZY RELIABILITY ANALYSIS OF SYSTEMS
}

\author{
NGUYen VAN Pho \\ Hanoi University of Civil Engineering
}

\begin{abstract}
The interference model of the fuzzy reliability analysis has been the focus of some researches. In this paper, the author proposed a general interference model for fuzzy reliability analysis, which based on the safety condition, not use the stress-strength interference model. Therefore, the proposed model can apply for every reliability problems of the systems.
\end{abstract}

\section{INTRODUCTION}

In 1965, Zadeh proposed the theory of fuzzy sets [1]. Since the publication of the seminal work "Fuzzy sets" by Zadeh, this subject has been the focus of many research fields, which have contributed to various practical applications $[2,3,4, \ldots]$.

The fuzzy sets theory in reliability analysis is studied $[5,6,7, \ldots]$. Reliability analysis of mechanical structure require some information on the probability distribution of stress in the structure and material strength.

We know it is difficult to obtain the distribution laws of the stress and strength for complicated mechanical structure.

There are many methods, such as Monte-Carlo method [8], FEM method [9] and other [10] to solve this problem. It has been approved that the distribution of material strength generally follows a normal distribution [11], which can be obtained from a enough series of testing data.

The stress in the structure is related to several other variables, such as structure sizes, material properties and external loads, and in most cases, it is difficult to express them in a mathematical formula, and its related variables are not random variables, but fuzzy variables or other uncertain variables.

In this paper, the author proposed a general interference model of fuzzy reliability analysis of mechanical system. The general interference model based on the safety condition or performance function in order to find failure probability. Therefore, the proposed model can apply for a large class of the reliability problems.

\section{THE CLASSICAL STRESS-STRENGTH IN INTERFERENCE MODEL}

In the classical reliability analysis, the stress-strength interference model is proposed by N.C Streleski [11]. In this model, the strength and stress are modeled as two random variables with given distribution functions.

Fig. 1, shows a simple case considering two variables. (one relating to the demand on the system, e. g., load on the structure, $S$, and the other to the capacity of the system, e. g., resistance of the structure $R$ ).

Both $R$ and $S$ are random in nature, their randomness is characterized by their means $\mu_{s}$ and $\mu_{R}$, standard deviations $\sigma_{S}$ and $\sigma_{R}$, and corresponding probability density functions $f_{S}(s)$ and $f_{R}(r)$, respectively. 
An overlap will exist between the curves where failure may occur due to the possibility of strength $R$ being less than stress $S$.

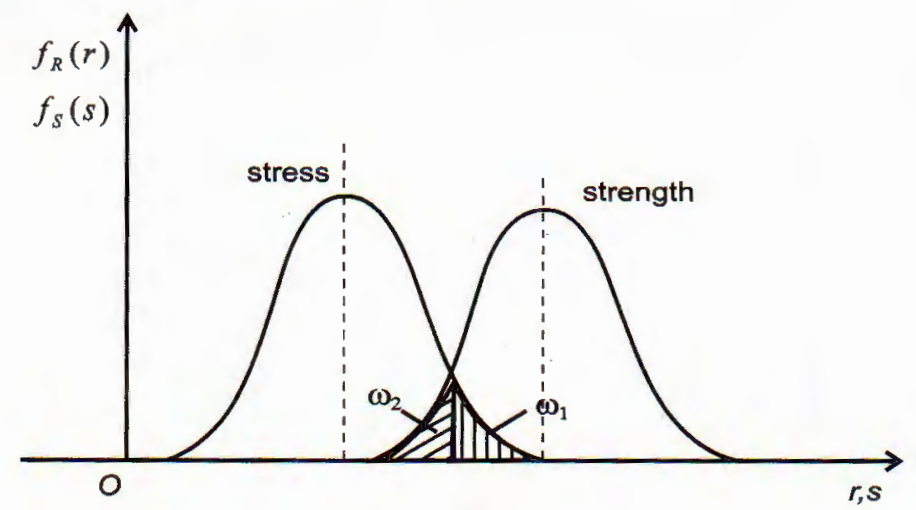

Fig. 1. The unreliable region

Fig. 1 shows the region of "unreliability", at the point of the intersection of the density curves $s_{0}=r_{0}$, it divides region of "unreliability" into two parts, their areas respectively.

$$
\left.\begin{array}{l}
\omega_{1}=\int_{S_{0}}^{\infty} f_{S}(s) d s \\
\omega_{2}=\int_{-\infty}^{R_{0}} f_{R}(r) d r
\end{array}\right\}
$$

The failure probability $P_{f}$ satisfies the following inequality

$$
P_{f}>\omega_{1} \omega_{2}
$$

According to B.P. Muller [11], the safety probability $P_{S}$ satisfies the following inequality

$$
P_{S}>\left(1-\omega_{1}\right)\left(1-\omega_{2}\right)
$$

From (2.2) and (2.3), we have

$$
\omega_{1} \omega_{2}<P_{f}<\omega_{1}+\omega_{2}-\omega_{1} \omega_{2}
$$

where $\omega_{1}, \omega_{2}$ are substantially small values. Product $\omega_{1} \omega_{2}$ is substantially small value also, it have small degree is greater than $\omega_{1}$ and $\omega_{2}$.

Therefore, we have an approximate evaluation

$$
0<P_{f}<\omega_{1}+\omega_{2}
$$

In the practice, we can select an upper margin value of the failure probability is $P_{f}^{+}=$ $\omega_{1}+\omega_{2}$ for the valuation. 


\section{THE FUZZY STRESS-RANDOM STRENGTH INTERFERENCE MODEI}

Similar classical interference model, Li Bing, Xhu Meilin, Xu-Kai [7] proposed a fuzzy stress-random strength interference model Fig. 2. In which, the density function $f(x)$ replaced by membership function of the stress. By similar way, we can establish other interference models. For example, random - fuzzy interference model (Fig. 3), fuzzy-fuzzy interference model (Fig. 4).

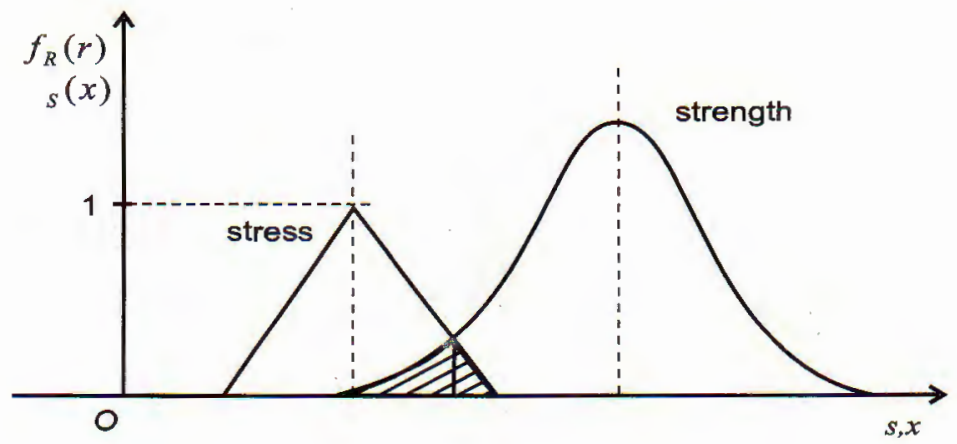

Fig. 2. The fuzzy stress-random strength interference model

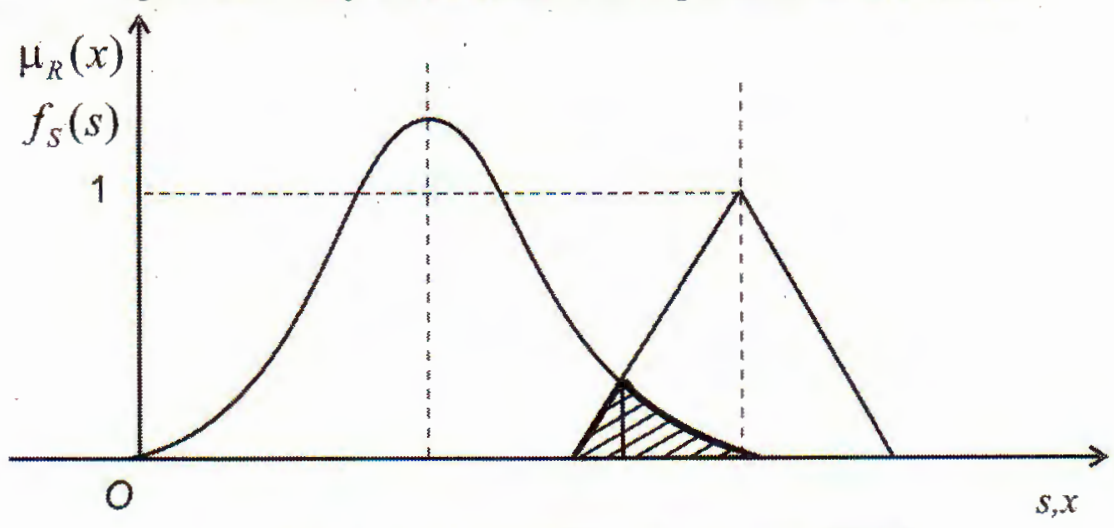

Fig. 3. The random - fuzzy interference model

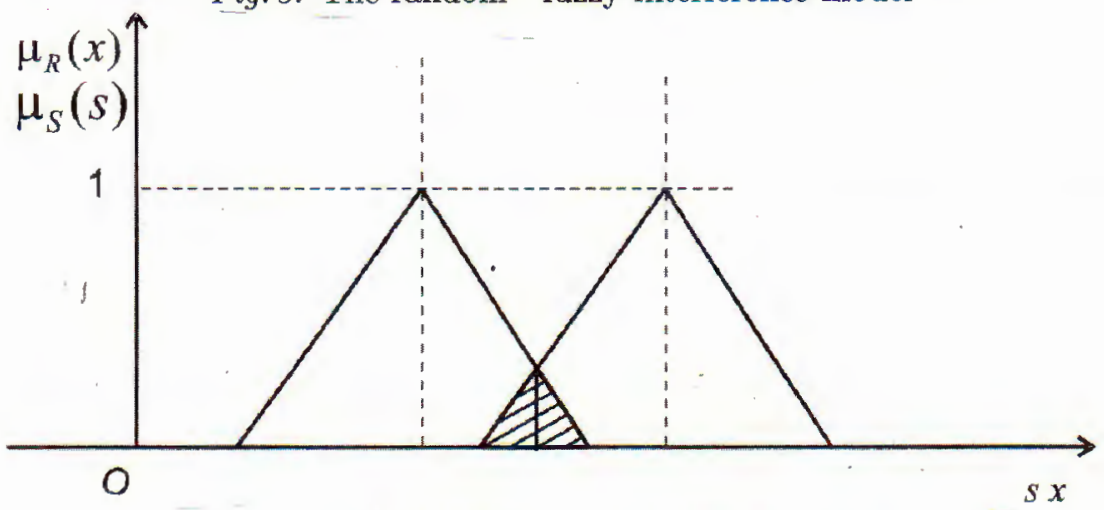

Fig. 4. The fuzzy-fuzzy interference model

In order to find $\omega_{1}$ and $\omega_{2}$, we solve equation

$$
f_{S}(s)=f_{R}(r),
$$


where $f_{S}(s)$ and $f_{R}(r)$ are density functions or the membership functions of the stress or the strength. The root of the equation (3.1) is the value $S_{0}=R_{0}$. According to formula (2.1), we can easily find $\omega_{1}$ and $\omega_{2}$.

\section{THE GENERAL INTERFERENCE MODEL}

As we know, in some simple cases the reliability of a structure is determined by only two independent random variables $R$ and $S$, hence the safety condition is $R-S>0$.

In most cases of practice, the safety condition can not be separated into two parts: load effect and resistance material.

In the general case, the safety condition is presented under form:

$$
F(\vec{X})>0
$$

where $X_{i}(i=1,2, \ldots, n)$ are fundamental variables. The safety $\operatorname{margin} M=F(\vec{X})$ and safety condition is $M(\vec{X})>0$ or

$$
M(\vec{X})-0>0
$$

Consequently, we separated $M(\vec{X})$ into two parts: $M(\vec{X})$ and 0 . Zero is a deterministic value, we can be considered zero as a fuzzy number with the spread $C=0$ and its membership function can be chosen as follows (Fig. 5).

$$
\mu_{(0)}(x)= \begin{cases}0 & x \neq 0 \\ 1 & x=0\end{cases}
$$

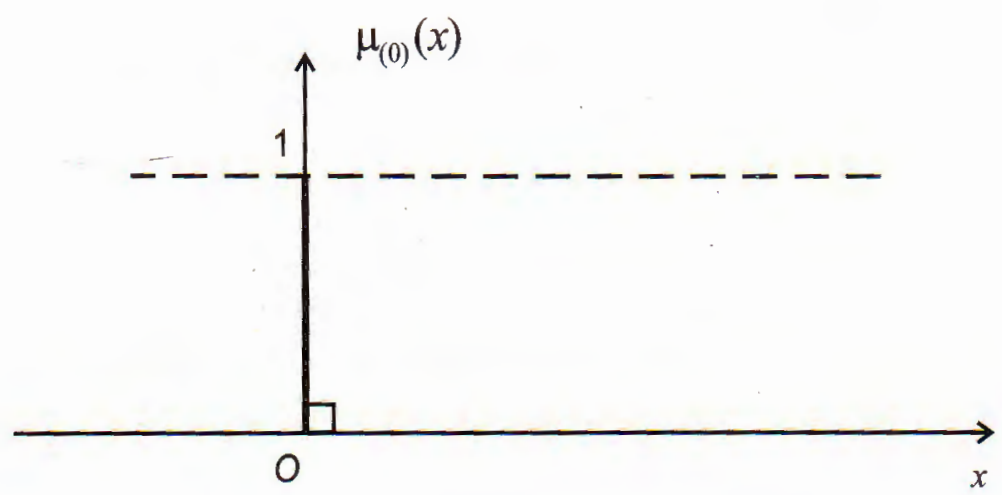

Fig. 5. The graph of the membership function for Zero

In general, $M(\vec{X})$ is function of the deterministic, random and (or) fuzzy variables.

Therefore $M(\vec{X})=F(\vec{X})$ is a fuzzy function of fundamental variables of the problem. The membership function of $M(\vec{X})$ is found by fuzzy linear regression method $[7,12,13]$. The interference model of $M(\vec{X})$ and Zero can show on Fig. 6.

In the case, the membership function is symmetric triangular, when use the finite element analysis as a "number experiment" tool, and to find directly by linear regression method, the fuzzy reliability of the mechanical structure can be evaluated. 


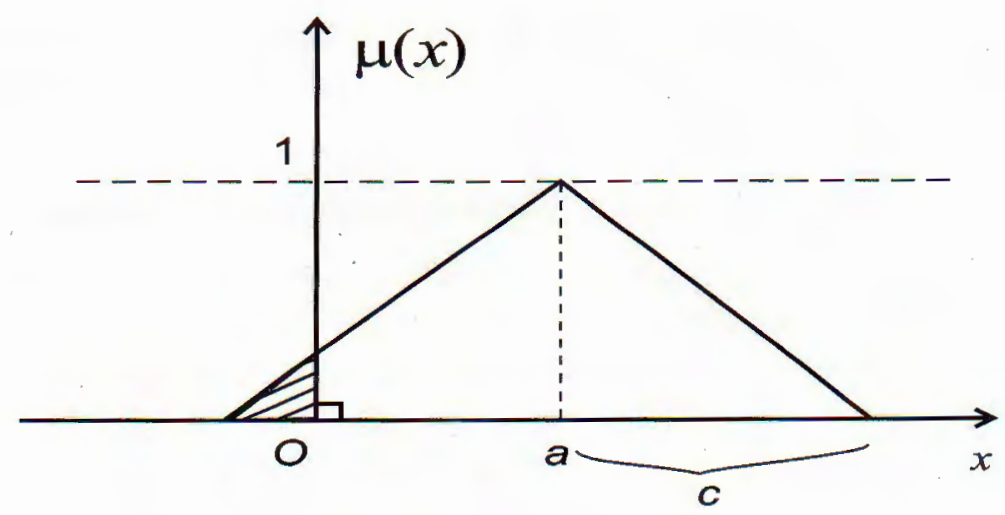

Fig. 6. The interference model of $M(\vec{X})$ and Zero

Modeling fuzzy linear systems has been addressed in fuzzy linear regression analysis $[12,13]$, the following model shows the dependence of the output variable on the input variables.

$$
\dot{M}=\tilde{Y}=f(x, \tilde{A})=\tilde{A}_{0}+\tilde{A}_{1} x_{1}+\ldots+\tilde{A}_{n} x_{n}
$$

where $\tilde{M}$ is the fuzzy output, $\vec{x}=\left[x_{1}, x_{2}, \ldots, x_{n}\right]^{T}$ is real-valued input vector, and $\tilde{A}=$ $\left\{\tilde{A}_{0}, \tilde{A}_{1}, \ldots, \tilde{A}_{n}\right\}$ is set of fuzzy numbers.

Then the membership function of $\tilde{Y}$ defined in (4.3) has the form:

$$
\mu_{\tilde{Y}}(y)=\left\{\begin{array}{cc}
1-\frac{y-\left(x^{T} a^{c}+a_{0}^{c}\right)}{|x|^{T} a^{s}+a_{0}^{s}}, & \left(x^{T} a^{c}+a_{0}^{c}\right) \leq y \leq\left(x^{T} a^{c}+a_{0}^{C}+|x|^{T} a^{S}+a_{0}^{S}\right), \\
1-\frac{\left(x^{T} a^{C}+a_{0}^{C}\right)-y}{|x|^{T} a^{S}+a_{0}^{S}}, & \left(x^{T} a^{C}+a_{0}^{C}-|x|^{T} a^{S}-a_{0}^{S}\right) \leq y \leq\left(x^{T} a^{C}+a_{0}^{C}\right) . \\
0 \quad \text { otherwise } &
\end{array}\right.
$$

where $|x|=\left[\left|x_{1}\right|,\left|x_{2}\right|, \ldots,\left|x_{n}\right|\right]^{T}$ and $\mu_{\tilde{Y}}(y)=0$ when $|x|^{T} a^{S}+a_{0}^{S} \leq\left|y-\left(x^{T} a^{C}+a_{0}^{C}\right)\right|$, $a_{i}^{C}$ is the center and $a_{i}^{S}$ is the spread of $\tilde{A}_{i}, \tilde{A}=\left\{a^{C}, a^{S}\right\}$.

For example, similar in the work [12], we will study the following simple case.

Let us consider the safety margin is fuzzy linear function with symmetrical triangular coefficients is given by

$$
\tilde{Y}=\tilde{A}_{0}+\tilde{A}_{1} x_{1}+\tilde{A}_{2} x_{2}-4
$$

with $\tilde{A}_{0}=[-2,0], \tilde{A}_{1}=[1,3], \tilde{A}_{2}=[2,6]$ where $\tilde{A}_{i}=\left[a_{i}^{L}, a_{i}^{U}\right], x=[1,2]^{T}, a_{i}^{L}$ is the lower limit, $a_{i}^{U}$ is upper limit.

From the given information, we can find $a_{0}^{C}=-1, a_{1}^{C}=2, a_{2}^{C}=4, a_{0}^{S}=1, a_{1}^{S}=$ $1, a_{2}^{S}=2$. Then the center and spread of $\tilde{Y}$ can be calculated as follows:

+ The center of $\tilde{Y}=5$

+ The spread of $\tilde{Y}=6$ 


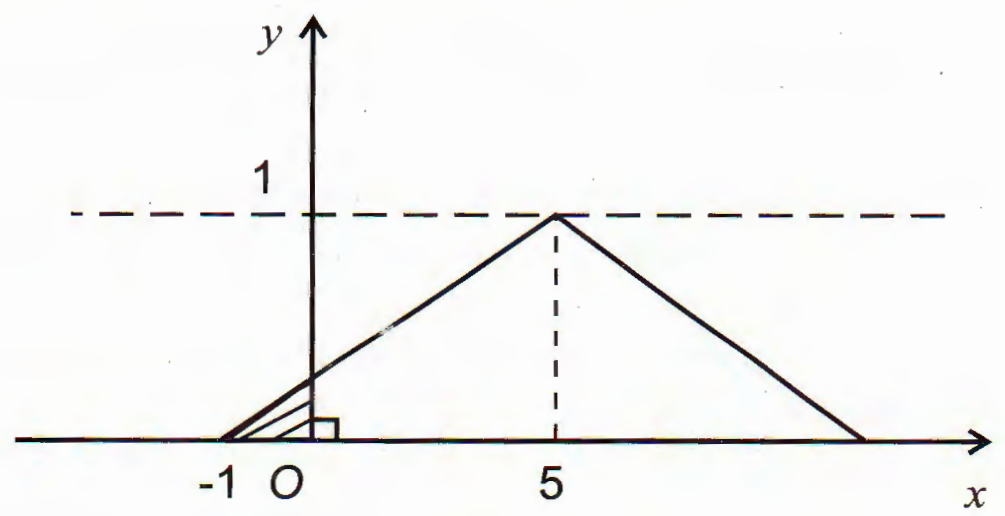

Fig. \%. The interference model for example

From Fig. 7 , we have $\omega=\frac{1}{2} \cdot 1 \cdot \frac{1}{6}=\frac{1}{12}$.

According to $(2.5)$, we have $P_{f}<\frac{1}{12}$ and $P_{f}^{+}=\frac{1}{12} \Rightarrow P_{S}=1-P_{f}=1-\frac{1}{12}=$ 0.916666 .

\section{CONCLUSION}

The general interference model proposed in this paper can apply for every safety condition and for every form of the membership function in the fuzzy reliability analysis of the system. easily.

Application of the general interference model lets us calculate the reliability problems Acknowledgment. This publication is completed with financial support from the National Basic Research Program in Natural Science.

\section{REFERENCES}

1. L. A. Zadeh, Fuzzy Sets, Information and Control, 8-1965.

2. M. Jamshidi, N. Vadiee, T. Ross (Eds), Fuzzy Logic and Control: Software and Hardware Applications, Prentice-Hall, Englewood Cliffs, NJ. 1993.

3. Nguyen Van Pho, Mechanics in situation of the fuzzy information, Proceeding of the Seventh National Conference on Solid Mechanics, Do Son, 8, 2004, Vietnam.

4. H. J. Zimmerman, Fuzzy Set Theory and its Applications, Kluwer Acad. Pub., 1991 (2nd. Ed.).

5. Nguyen Van Pho, Nguyen Dinh San, Nguyen Thac Vu, A new method for fuzzy reliability analysis of constructions, J. Science and Technology for Building (3) (2005) 7-14.

6. Shi Ming Chen, Analyzing Fuzzy system Reliability using Vague set Theory, Inter. J. of Applied Science and Engineering 1 (2003) 82-88. 
7. Li Bing, Zhu Meilin, Xu Kai, A practical engineering method for fuzzy reliability analysis of mechanical structures, Reliability Engineering and System Safety 67 (2000) 34-315.

8. R. Y. Robinstein, Simulation and Monte - Carlo Method, New York. Wiley, 1991.

9. O. C. Zienkiewiez, R. L. Taylor, The Finite Element Method in Structural and Continuous Mechanics, M. C. Graw-Hill, 1990.

10. H. Chang, Y, Shi, A practical reliability analysis method for Engineers, Reliability Engineering and System Safety 47 (1995) 93-95.

11. V. V Bolotin, Statistical Method in Structural Mechanic, Moscow 1995 (In Russian).

12. K. K. Yen, S. Ghoshray, G. Roig, A linear regression model using triangular fuzzy number coefficients, Fuzzy Sets and System 106 (1999) 167-177.

13. H. Tanaka, S. Vejima, K. Asai, Linpar Regression Analysis with Fuzzy Model, IEEE Trams. System Man Cybernet 4 (1982) 903-907.

Received October 10, 2005

\section{MÔ HİNH GIAO THOA TỔNG QUÁT CƯA PHÂN TÍCH Độ TIN CẬY MỜ}

Mô hình giao thoa trong phân tích độ tin cậy của công trình đã được nghiên cứu, song chỉ trong điều kiện an toàn được tách ra thành hai phần: hiệu quả tải trọng và khả năng chịu lực. Trong bài này tác giả đề nghị một mô hình giao thoa tổng quát bằng cách đựa vào diều kiện an toàn, không đòi hơi phân tích thành hai thành phần. Vì vậy mô hình đề nghị trong bài này có thể dùng để giải bài toán độ tin cậy cho điều kiện an toàn tồng quát và hàm lệ thuộc mờ bất kỳ. 